\title{
Gender, Masculinity-Femininity, and Emotional Intimacy in Same-Sex Friendship ${ }^{1}$
}

\author{
Dorie Giles Williams ${ }^{2}$ \\ University of Michigan
}

Using multiple regression techniques, this research examines the relationship of gender and of masculinity-femininity to self-reported emotional intimacy in same-sex friendship among male and female college students, a segment of the population for which friendship is thought to be of particular salience. Findings indicate that, as hypothesized, males report significantly lower levels of emotional intimacy in same-sex friendship than do females. Masculinity, defined in terms of "instrumental" qualities, has little effect on the degree of reported intimacy, while femininity, defined in terms of "expressive" qualities, is positively associated with intimate friendship. Findings for differences among individuals classified on combinations of masculinity and femininity are also presented. Results are interpreted in view of sex-role expectations which appear to prohibit displays of emotional vulnerability among men.

Literature on same-sex friendship suggests that men's friendships may often be characterized by less intimate modes of interaction than are friendships among women. These gender differences in modes of relating to same-sex friends are usually attributed to sex-role expectations, which are thought to require emotional control in male interactions, while permitting expressive behaviors in female exchange (David \& Brannon, 1975). To the degree that males conform to sex-role requirements, they are thought to be inhibited in

'The author wishes to thank Frank Bean for his many contributions to the research on which this paper is based. Appreciation is also extended to Susan Marshall for comments on an early draft.

-To whom correspondence should be addressed at Survey Research Center, Institute for Social Research, University of Michigan, Ann Arbor, Michigan 48106. 
forming close relationships with other men. Enactment of gender roles, however, may be thought to vary according to the individual's orientations toward masculinity and femininity (Bem, 1974; Spence \& Helmreich, 1978). To the extent that these aspects of the self-concept are manifest in specific social behaviors, one might expect an instrumental (masculine) or expressive (feminine) orientation to have consequences for interpersonal interaction. The present research considers the relationship of gender and of masculinity-femininity to self-reported modes of interaction among same-sex friends. Its major purpose is to test hypotheses concerning the effects of gender and of masculinity-femininity (and their combinations) on emotional intimacy in same-sex friendship.

\section{GENDER AND PERSONALITY DIFFERENCES IN SAME-SEX FRIENDSHIP}

A body of descriptive literature on same-sex friendship contends that male modes of interaction differ significantly from patterns of interaction among females (Lewis, 1978; Sattel, 1976; Fasteau, 1975; Farrell, 1975; Goldberg, 1975). Although men are said to enjoy and often to prefer the company of other men, their friendships are reportedly lacking in mutual self-disclosure, shared feelings, and other demonstrations of emotional closeness which are thought to characterize women's friendships. Activities among men appear to be based less on verbal communication than on "doing things" together (Pearce et al., 1974). Sports and games are said to play a central role in male activities because they provide an impersonal focus for male get-togethers and allow men to avoid personal confrontation. Conversations among men, when they do occur, are often said to include few revelations of personal feelings and problems. Proscriptions against emotional vulnerability are said to restrict topics of conversation to those which are impersonal and, therefore, "safe" (Fasteau, 1975, p. 7). Verbal declarations of liking, as well as nonverbal demonstrations of affection, are often said to be absent in male friendship (Lewis, 1978).

Empirical evidence for these specific interaction patterns in same-sex friendship is generally lacking; studies do, however, suggest that there are qualitative differences in male and in female friendships throughout the life cycle. Studies of children, for example, often find that boys are more likely to have a number of friends with whom to share different activities, while girls are more likely to have a single best friend with whom to share feelings and confidences (Seiden \& Bart, 1975). In adolescence, males tend to interact in larger groups, while females tend to interact in dyads (Douvan \& Adelson, 1966). Studies of college students and other adults suggest that 
men's friendships may often be less personal, and possibly less rewarding, than are women's friendships (Wheeler \& Nezleck, 1977; Pleck, 1975; Olstead, 1975; Powers \& Bultena, 1976; Booth, 1972), involving little in the way of intimate self-revelations (Jourard, 1971). Other studies suggest that men may generally have less intimate friendships with both sexes than do females (Nye, 1976; Knupfer et al., 1966).

Gender differences in friendship patterns are often thought to have their origins in early socialization in which individuals internalize behavioral expectations and personality traits considered appropriate for their respective sexes. Boys appear to be subject to greater pressures for sex-role conformity than are girls (Maccoby \& Jacklin, 1974), pressures which may often take the form of requiring males to avoid "feminine" behavior (Hartley, 1959; Lynn, 1969). This "negative" socialization is often thought to result in the rejection by males of anything associated with females, including expressive orientations which are often thought to be central in defining the female role (Parsons, 1955; Bakan, 1966; Spence \& Helmreich, 1978). While women are permitted to express emotions in interpersonal interactions, men are often said to be discouraged from displaying any but the more aggressive emotions, particularly those that suggest vulnerability (David \& Brannon, 1975). Because of proscriptions on self-revelation in interpersonal exchange, men may find it difficult to establish close relationships with male friends.

These patterns of interaction are thought to be reinforced and maintained by the structure of adult roles (e.g., competitive work roles). While most observers attribute male modes of interaction in friendship to internalized norms, Sattel (1976) argues that male inexpressiveness is a conscious attempt by males to maintain privilege and power in relationships with others, so that even in friendship, men learn to withhold emotional expression. Whether these patterns of behavior are viewed as an acting out of internalized norms or as a dominance strategy, males might be expected to report less intimate modes of interaction with same-sex friends than females report. Thus, the first hypothesis to be tested in this research is that males, in comparison with females, will report less emotional intimacy in same-sex friendship.

The existence of different role expectations for the two sexes is well documented. It is also clear, however, that even the strongest and most explicit role expectations are subject to modification by individual role occupants (House, 1981). Individuals often redefine roles when there is incongruence or lack of fit between individual personality and role demands. Previous research suggest that orientations of masculinity (defined in terms of "instrumental" qualities) and femininity (associated with "expressive" characteristics) may be thought to influence behaviors in specific social contexts such as friendship, since these constellations of traits 
have been found to be associated with a number of gender-related outcomes (Spence \& Helmreich, 1978). ${ }^{3}$ To the extent that individuals' self-concepts incorporate instrumental qualities which focus on self-enhancement and external mastery, they might be expected to respond to others in detached, impersonal ways and to report less emotional intimacy in same-sex friendship. Individuals whose self-concepts emphasize expressive, personoriented qualities may be likely to manifest these characteristics in friendship in a manner conducive to the development of intimacy. Therefore, it is hypothesized that masculinity is negatively related and femininity is positively related to emotional intimacy in same-sex friendship for both sexes.

The above hypotheses are based on the content of masculinity and femininity conceptualized as distinct sets of internal response predispositions which may be thought to be manifest in specific role behaviors (Helmreich et al., 1979). Previous research suggests, however, that individuals may vary in a particular response according to the manner in which they combine these sets of attributes in their self-concepts (Bem, 1974; Spence \& Helmreich, 1978). Sex-typed males and females (high on own-sex, low on opposite-sex characteristics) are often thought to exhibit responses that are more stereotypically masculine or feminine, respectively, whereas androgynous individuals (high on both masculinity and femininity) are expected to respond in instrumental or expressive ways as the occasion demands, although evidence for the greater flexibility of androgynous individuals in comparison with other categorical types is far from conclusive (e.g., see Helmreich et al., 1979).

The present research is concerned with modes of relating to one's "best" or "closest"' same-sex friends, which would appear to call for an expressive orientation. If androgynous individuals display flexibility in their interpersonal interactions, both males and females might be expected to report relatively high levels of emotional intimacy in friendship, despite their high levels of masculinity. Sex-typed males and females and cross-sex-typed individuals (high in orientations of the opposite sex) might be expected to respond in terms of their dominant orientations. This suggests that androgynous and cross-sex-typed (feminine) males will report higher levels of emotional intimacy than males of other categorical types. Androgynous and sex-typed (feminine) females are expected to report greater emotional intimacy in friendship than females of other types. ${ }^{4}$

\footnotetext{
${ }^{3}$ In suggesting this possibility, I am adopting the position that it is sometimes useful to postulate relatively stable internal attributes (in this case, personality characteristics) that have some degree of situational generality. While recognizing the influence of situations and other factors on behavioral outcomes, many researchers continue to argue for the usefulness of such concepts in predicting certain types of outcomes (see Spence \& Helmreich, 1978, p. 15).

${ }^{4}$ Given the hypothesized relationship of masculinity (negative) and of femininity (positive) to the dependent variable, it follows that feminine individuals (low on masculinity, high on femininity) will report high levels of emotional intimacy. The hypothesis for androgynous
} 


\section{DATA AND METHODS}

The literature on friendship suggests that such relationships may be most important to individuals during adolescence and young adulthood (DuBois, 1974; Shulman, 1975; Bell, 1975). It is during the period between sexual maturity (early adolescence) and the assumption of adult social roles (marriage, occupation, parenthood) that nonfamilial relationship are likely to be most highly valued (DuBois, 1974). Since the majority of college students is likely to be located within this life stage, a focus on this segment of the population appears warranted. Data for the study were thus obtained from 508 undergraduate students ( 205 males, 303 females) at the University of Texas at Austin. ${ }^{5}$ Respondents volunteered to complete an instrument that included a measure of masculinity-femininity, a 24-item measure of emotional intimacy in same-sex friendship, and questions soliciting sociodemographic data.

The independent variables are gender, masculinity, and femininity; the latter variables are measured by the Personal Attributes Questionnaire (PAQ) developed by Spence and Helmreich (1978). The PAQ contains two eight-item scales designed to tap these dimensions of personality. Each scale consists of trait descriptions with five response categories coded $0-4$, with high scores denoting high masculinity and femininity, respectively. In order to assess the dimensionality of the scales as well as the scalability of the items for the present data set, responses to the 16 items were subjected to a factor analysis using the factor analysis subroutine in SPSS (Nie et al., 1975 ) with oblique rotation (delta $=0$ ). Consistent with a dualistic conception of masculinity-femininity, results supported a two-factor solution. ${ }^{6}$ Measures of masculinity and femininity are thus computed by summing responses to the eight characteristic items in each scale. Internal consistency reliabilities (Cronbach's alpha) were computed for the two scales, resulting in coefficients of .792 for masculinity and .745 for femininity.

individuals, however, assumes that the negative effects of high masculinity are tempered by the effects of high femininity due to the flexibility of androgynous persons.

${ }^{5}$ The background characteristics of the sample are as follows: White $(94 \%)$; single $(94 \%)$; Protestant $(46 \%)$ or Catholic $(30 \%)$, middle to upper-middle class (median parental income, $\$ 49,532$; median for father's education, 15.9 years); median age, 20.2 years; and median education, 14.2 years. While probability sampling would be highly desirable in this study, resource limitations precluded the adoption of this method; therefore the applicability of research findings may be limited and caution is advised in generalizing to populations different from the one studied. The homogeneity of the sample, however, has the advantage of allowing the effects of the independent variables to be assessed in the circumstances where variation in sociodemographic characteristics is minimized.

${ }^{6}$ Iterns loading on Factor 1 (Masculinity) were independent (.534), active (.508), competitive (.503), decisive (.622), never gives up (.607), self-confident (.715), feels superior (.541), and stands up under pressure (.534). Items loading on Factor 2 (Femininity) were emotional (.365), devotes self to others (.428), gentle (.403), helpful (.539), kind (.558), aware of others' feelings (.685), understanding (.725), and warm (.609). 
A 24-item Likert-type index (with responses scored 0-4) was constructed to assess the dependent variable, conceptualized as modes of interaction which appear to indicate emotional intimacy in same-sex friendship. Items for the measure were derived from literature (cited above) on same-sex friendship. Respondents were asked to respond in terms of their best or closest friends. Responses to the 24 statements were subjected to a factor analysis using the factor analysis subroutine (PA2) in SPSS (Nie et al., 1975) in order to determine the dimensionally and scalability of items. The initial solution revealed one factor with an eigenvalue of 7.17, accounting for $69.7 \%$ of the common variance (32.2\% of the total variance was explained by this factor). Four of the items, however, loaded higher on a second factor than on the first. These items were deleted and responses to the remaining 20 statements were subjected to a separate factor analysis. The unrotated solution revealed one factor with an eigenvalue of 6.61, accounting for $84.3 \%$ of the common variance ( $36 \%$ of the total variance was explained by factor 1). Since subsequent factors added negligibly to explained variance, scores on the 20 items were summed to create composite socres, with higher scores indicating greater emotional intimacy in same-sex friendship. Scores on the index ranged from 6 to $80(\bar{X}=56.39, \mathrm{SD}=$ 12.08). Table I displays the 20 items with their factor loadings. Internal consistency reliability for the index (Cronbach's alpha) is .901.

In order to test the hypotheses, multiple regression analysis is employed. Scores on the emotional intimacy scale are first regressed on the measures of masculinity and femininity while controlling for father's education. The latter variable is included as a measure of socioeconomic status (SES), since SES had been found to be associated with the rigidity of sex-role distinctions (Goode et al., 1971) and may also be thought to be associated with emotional intimacy in friendship (e.g., more highly educated individuals may be more self-expressive) and thus might be thought to confound the results. In a second equation, a dummy variable for gender (with males coded 1 , females coded 0 ) is included. This equation allows a test of the differential effects of gender along with those of masculinity and femininity on the dependent variable. In a third equation, the results of including interaction terms for gender and masculinity and for gender and femininity are assessed. The inclusion of these terms enables a test for gender differences in the effects of masculinity and femininity on the dependent variable (although no gender differences are hypothesized).

In order to test hypotheses concerning the effect of combinations of masculinity and femininity on the dependent variable, respondents are first classified according to their scores above and below the median on the two scales using college student norms established by Spence and Helmreich (1978, p. 36). These scores are 21 for masculinity and 23 for femininity. Among males, $36 \%$ are classified as sex typed, $39 \%$ as androgynous, $11 \%$ as cross-sex typed, and $14 \%$ as undifferentiated. Among females, the 
Table I. Unrotated Factor Loadings: Emotional Intimacy in Same-Sex Friendships (20 Items $)(N=529)$

Item

Factor 1

1. When my friends and I are together, we spend most of our time participating in some type of sport or game.

2. With my best friends, conversation usually stays on a causal level and doesn't involve our personal feelings.

3. When I am excited or happy about something, I usually tell my best friends about it, even it it's rather unimportant.

4. It's very important to me that my friends understand my ideas and feelings.

5. I often confide in my friends about my dreams for the future

6. When I have a problem, I usually discuss it with my best friends.

7. My friends and I often get together just to talk.

8. I sometimes hide my real feelings so my friends won't know when I'm anxious about something.

9 It doesn't matter if my friends understand my feelings as long as we like to do the same kinds of things.

10. It would humiliate me if my best friend saw me crying about a serious emotional problem.

11. My friends and I often tell each other how much our friendship mean to us.

12. My friends and I talk more about everyday events than about our personal lives.

13. My friends and I are usually involved in some activity when we are together and don't spend a lot of time just talking.

14. When I am depressed, I usually let my best friends know how I feel.

15. As long as we have a good time together, I don't care if my best friends know what I'm really like or not.

16. It would embarrass me to hug my best friend.
17. When I feel unsure of myself, I am careful not to let my friends know.

18. I have told my best friend that I really like her/him

19. My friends and I talk mostly about our feelings and personal lives.

20. I like my friends to be "happy-go-lucky" and not involve me in their problems.

Eigenvalue

comparable classifications are $30 \%$ as sex typed, $46 \%$ as androgynous, $10 \%$ as cross-sex typed, and $14 \%$ as undifferentiated.

The median-split method of classifying respondents is chosen both because it provides conceptual clarity in communicating differences among categories and because it permits comparison with much previous research in which the effects of categorical types are assessed. Dummy variables were created on the basis of these classifications and entered into regression equations with the undifferentiated serving as the reference category. Separate regression models are estimated for males and females in order to provide a straightforward assessment of the hypothesized effects within 


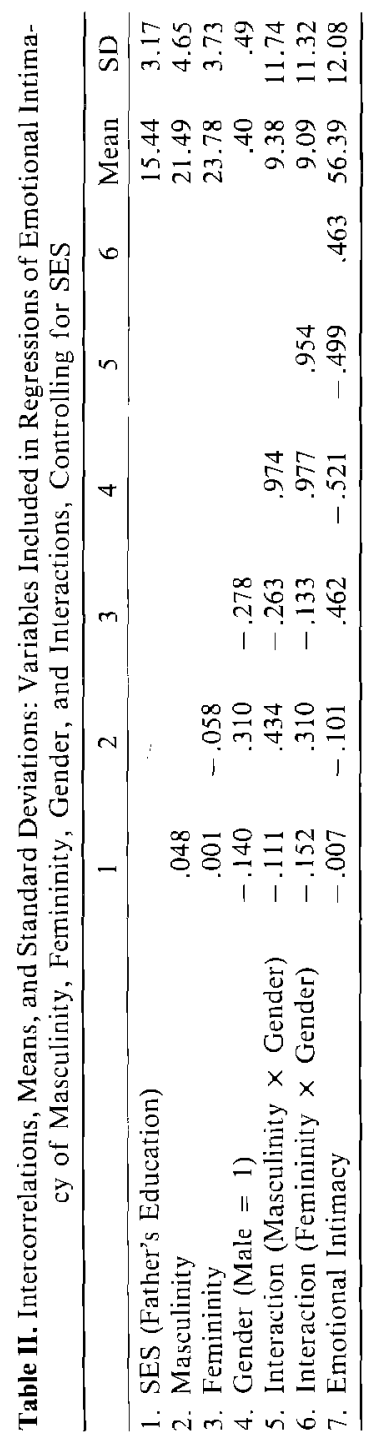


each gender. A series of one-tailed difference-of-means tests is performed in order to assess differences among all the categorical types.

\section{RESULTS}

Table II displays the intercorrelations, means, and standard deviations of variables included in the regression models constructed to test hypotheses concerning the effects of gender, masculinity, femininity, and their interactions. Table III displays the results. The second column in Table III shows the results of testing for the effects of masculinity and femininity while controlling for father's education (as a proxy for SES of the family of origin). The results are consistent with the hypotheses stated above; i.e., masculinity is negatively related to the expression of intimacy ( $b$ $=-.194, p<.05)$ and femininity is positively related to self-reported intimacy $(b=1.482, p<.001)$ among same-sex friends. The coefficient for masculinity, however, is small. Approximately $22 \%$ of the total variance is explained by this model $\left(R^{2}=.219\right)$.

The third column in Table III displays the results of including a dummy variable for gender in the regression equation, with males coded 1 and females coded 0 . The unstandardized regression coefficient for gender $(b=-11.229)$ is significant at the .001 level of probability, indicating that males, as hypothesized, report significantly less emotional intimacy in same-sex friendship than do females.

The coefficient for masculinity is not significant in this model; when gender is controlled, the effects of masculinity become nonsignificant, since males tend to score higher on masculinity than do females. The coefficient for femininity is reduced by more than one-fourth when the effects of gender are considered (since females tend to score higher on both femininity and emotional intimacy). The inclusion of gender in the model increases explained variance to approximately $39 \%\left(R^{2}=.388\right)$.

In the fourth column in Table III, the results of including interaction terms for gender and masculinity and for gender and femininity are displayed. As can be seen, the coefficients for the interaction terms are not significant and the inclusion of these terms does not add to explained variance $\left(R^{2}=.388\right) .{ }^{4}$ These findings thus indicate no male-female differences in the direction or the magnitude of the effects of masculinity and femininity on the expression of intimacy in same-sex friendship.

Table IV displays the means, standard deviations, and intercorrelations of variables included in the regression models constructed to test hypotheses concerning the effects of the categorical types on the dependent variable (controlling for SES). Table $\mathrm{V}$ displays the results of the separate analyses for males and females. As can be seen from the second column in 
Table III. Regressions, Emotional Intimacy and Masculinity, Femininity, Gender, and Tests for Interaction, Controlling for SES (Unstandardized Coefficients) ${ }^{a}$

\begin{tabular}{lccc}
\hline \multicolumn{1}{c}{ Variable } & 1 & 2 & 3 \\
\hline SES (Father's Education) & -.164 & $-.286^{d}$ & $-.289^{d}$ \\
& $(-.004)$ & $(-.075)$ & $(-.076)$ \\
Masculinity & $-.194^{d}$ & -.165 & .182 \\
& $(-.075)$ & $(-.063)$ & $(.070)$ \\
Femininity & $1.482^{c}$ & $1.096^{c}$ & $1.162^{c}$ \\
& $(.457)$ & $(.338)$ & $(.359)$ \\
Gender (Male = 1, Female =0) & $-^{b}$ & $-11.229^{c}$ & -6.920 \\
& & $(-.457)$ & $(-.281)$ \\
Interaction (Masculinity $\times$ Gender) & $-{ }^{b}$ & $-{ }^{b}$ & -.043 \\
Interaction (Femininity $\times$ Gender) & $-{ }^{b}$ & $-{ }^{b}$ & $(-.042)$ \\
& & & -.143 \\
Regression constant & 25.58 & 35.72 & 33.80 \\
Multiple $R$ & .468 & .623 & .623 \\
$R^{2}$ & .219 & .388 & .388 \\
$F$ & $47.05^{c}$ & $79.70^{c}$ & $53.04^{c}$ \\
\hline
\end{tabular}

${ }^{a}$ Standardized coefficients in parentheses.

${ }^{b}$ Deleted from regression equation.

${ }^{c} p<.001$.

${ }^{d} p<.05$.

Table V, androgynous and cross-sex-typed males score significantly higher on emotional intimacy than undifferentiated males. There are no significant differences between sex-typed and undifferentiated males. As shown in the third column, sex-typed and androgynous female score significantly higher on emotional intimacy than undifferentiated females, with no significant differences between cross-sex-typed females and undifferentiated females. As hypothesized, androgynous and feminine individuals of both sexes score higher on emotional intimacy in same-sex

Table IV. Intercorrelations, Means, and Standard Deviations: Variables Included in Regressions of Emotional Intimacy on Combinations of Masculinity and Femininity, Controlling for SES

\begin{tabular}{|c|c|c|c|c|c|c|}
\hline & 1 & 2 & 3 & 4 & Mean & SD \\
\hline \multicolumn{7}{|l|}{ Males $(N=205)$} \\
\hline 1. SES (Father's Education) & & & & & 14.90 & 3.25 \\
\hline 2. Sex typed & .086 & & & & .36 & .48 \\
\hline 3. Androgynous & .009 & -.595 & & & .39 & .49 \\
\hline 4. Cross-Sex Typed & -.042 & -.258 & -.277 & & .11 & .31 \\
\hline 5. Emotional Intimacy & -.144 & -.144 & -177 & .114 & 48.75 & 10.91 \\
\hline \multicolumn{7}{|l|}{ Females $(N=303)$} \\
\hline 1. SES (Father's Education) & & & & & 15.80 & 3.06 \\
\hline 2. Sex Typed & -.004 & & & & .30 & .46 \\
\hline 3. Androgynous & .006 & -.608 & & & .46 & .50 \\
\hline 4. Cross-Sex Typed & -.024 & -.223 & -.311 & & .10 & .30 \\
\hline 5. Emotional Intimacy & -.057 & .132 & .131 & -.145 & 61.55 & 9.91 \\
\hline
\end{tabular}


Table V. Regression: Enotional Intimacy on Combinations of Masculinity and Femininity Controlling for SES

\begin{tabular}{lcc}
\multicolumn{3}{c}{ (Unstandardized Cocfficients) } \\
\hline & $\begin{array}{c}\text { Males } \\
(N=205)\end{array}$ & $\begin{array}{c}\text { Females } \\
(N=303)\end{array}$ \\
\hline SES (Father's Education) & $-.491^{c}$ & -.256 \\
Sex-Typed & 2.354 & $8.103^{a}$ \\
Androgynous & $6.708^{b}$ & $7.596^{a}$ \\
Cross-Sex Typed & $7.64^{b}$ & 1.809 \\
Regression constant & 51.79 & 59.47 \\
Multiple $R$ & .290 & .310 \\
$R^{2}$ & .084 & .096 \\
$F$ & $4.60^{b}$ & $7.93^{a}$ \\
\hline${ }^{a} p<.001$. & & \\
${ }^{b} p<.01$. & & \\
${ }^{c} p<.05$. & &
\end{tabular}

friendship than individuals of other categorical types. There was no evidence for interaction effects between SES (father's education) and the categorical groups; i.e., SES appears to have the same effect across categories (results not shown).

A comparison of category means (Table VI) reveals no significant differences between androgynous and cross-sex-typed males $(t=.48, p=$ ns) or between androgynous and sex-typed females $(t=.44, p=\mathrm{ns})$. Androgynous and cross-sex-typed males scored significantly higher on emotional intimacy than did sex-typed males $(t=2.87, p=.002$, and $t=$ $1.99, p=.028$, respectively). Similarly, androgynous and sex-typed females scored higher than cross-sex-typed females $(t=3.72, p=.001 ; t=3.33, p$ $=.001)$. Within each categorical type, females scored higher than their male counterparts, and these differences were highly significant $(p<.001)$.

\section{SUMMARY AND DISCUSSION}

One of the purposes of this research was to test hypotheses suggested by impressionistic accounts of friendship (e.g., Fasteau, 1975) that male

Table VI. Mean Scores on Emotional Intimacy by Categorical Type, Males and Females ${ }^{a}$

\begin{tabular}{lcc}
\hline & $\begin{array}{c}\text { Males } \\
(N=205)\end{array}$ & $\begin{array}{c}\text { Fernales } \\
(N=303)\end{array}$ \\
\hline Sex typed & 46.64 & 63.53 \\
Androgynous & 51.16 & 62.96 \\
Cross-sex typed & 52.31 & 57.29 \\
Undifferentiated- & & \\
44.83 & 55.56 & \\
\hline
\end{tabular}

${ }^{a}$ Unadjusted for effects of SES. 
modes of interaction differ from female patterns in specific ways. The findings reported above strongly support the contention suggested by this body of literature that male friendships are less intimate than female friendships, at least among this college-student sample. On the average, males in this sample tend to be less likely than females to confide in their close friends, to openly express feelings which suggest vulnerability, to demonstrate affection toward male friends, to emphasize mutual understanding and responsibility in their friendships, or to discuss personal issues in their conversations; and they are more likely to report spending time in active pursuits rather than in verbal communication. Although these findings provide no direct evidence for the effects of differential sex-role socialization of males and females, they are consistent with the theoretical perspective presented above. If males are motivated to detach themselves from that which is female in order to identify with the male role, they may come to reject modes of interaction in friendship which suggest vulnerability, thus inhibiting the sharing of self that is necessary for the development of intimacy.

There was no support in the present research for the hypothesized negative relationship between masculinity and the emotional intimacy measure; masculinity bears essentially no relationship to the degree of intimacy in friendship. This suggests that high levels of instrumental qualities per se do not necessarily result in detached, impersonal modes of relating to others among males or among females. Although some of the attributes subsumed under masculinity (e.g., competitive, feels superior) appear to preclude intimacy in friendship, others (e.g., active, self-confident) may be involved in acquiring the social skills necessary to the establishment of close relationships. These may balance out so that no strong relationship is found between masculinity and the emotional intimacy measure.

The finding that femininity bears a strong positive relationship to self-reported intimacy in friendship provides support for the idea that internalized predispositions may sometimes be manifest in specific social contexts. In the case of friendship, both males and females who consider themselves to be high in expressiveness tend to report interacting on a more intimate basis with same-sex friends. ${ }^{7}$ It is important to note, however, that role performance is likely to be influenced by a number of situational and attitudinal variables, including, as Spence and Helmreich (1978) point out, personal preference, attitudes toward the appropriateness of sex-role

\footnotetext{
${ }^{7}$ Since high bivariate correlations between the two interaction terms and between each interaction term and the gender component make it difficult to interpret the coefficients in this model, a number of regression models were estimated in which first one and then the other of the highly correlated variables were excluded (Lewis-Beck, 1980). None of these models indicated the presence of significant interaction effects.
} 
distinctions, and perceptions of positive and negative sanctions attached to particular behaviors. The inclusion of measures of these variables in studies assessing behaviors in the instrumental or expressive realm may provide important insights into the relative contributions of personality traits and other factors in determining role enactment.

Since previous research suggests that masculinity and femininity may combine in distinct ways to predict particular responses, differences among categorical types were also assessed. These findings may be interpreted in view of the findings for masculinity and femininity; i.e., the results appear to be due primarily to the effects of femininity. Males and females who reported high levels of femininity, regardless of whether they were high or low on masculinity, reported higher levels of emotional intimacy in friendship. These results underscore the importance of first assessing the relationships of masculinity and femininity separately before examining their combined effects, since this strategy provides more precise information concerning the direction and strength of these sets of attributes on a given dependent variable. In this study, for example, the hypothesis that androgynous individuals would demonstrate behavioral flexibility in their responses was based on the assumption that masculinity impacts negatively on emotional intimacy in friendship. The effects of femininity were expected to temper these negative effects. Since masculinity has little effect on emotional intimacy, the flexibility hypothesis is not sufficiently tested in this research. ${ }^{8}$

The finding that males report significantly lower levels of intimacy in friendship suggest that even when males incorporate a high degree of femininity in their self-concepts, they may be inhibited from behaving in expressive ways with male friends because of role expectations. Much of the literature on friendship (e.g., Fasteau, 1975) appears to assume that males generally desire closer friendship with other males but fear the consequences of behaving in ways that may be considered "unmanly." It has also been suggested, however, that male inexpressiveness is a conscious attempt to maintain dominance in interpersonal relationship (Sattel, 1976). The degree to which individuals desire intimacy in friendships and the relationship of intimacy to dominance appear to be important considerations for future research.

\footnotetext{
${ }^{3}$ Although the measures of femininity and of emotional intimacy may appear to have much in common, they are conceptually distinct since the research question concerns the degree to which global personality traits (instrumentality, expressiveness) predict responses in a specific social context (same-sex friendship). Moreover, the bivariate correlation between the two measures (.47; see Table III) is not inordinately high, suggesting that they are empirically distinct as well. While associated, the two measures do not appear to be measuring the same thing.
} 


\section{REFERENCES}

Bakan, D. The duality of human existence: An essay on Psychology and religion. Chicago: Rand McNally, 1976.

Bell, R. Swinging: Separating the sexual from friendship. In Interpersonal Relationship. New York: D. Van Nostrand, 1975, Chap. 6.

Bem, S. The measurement of psychological androgyny. Journal of Personality and Clinical Psychology, 1974, 42, 155-162.

Booth, A. Sex and social participation. American Sociological Review, 1972, 37, 183-192.

David, D., \& Brannon, R. The male sex role: Our culture's blueprint of manhood, and what it's done for us lately. In D. David \& R. Brannon (Eds.), The forty nine percent majority: The male sex role. Reading, Mass.: Addison-Wesley, 1976.

Douvan, E,, \& Adelson, J. The adolescent experience. New York: Wiley, 1966.

DuBois, E. The gratuitous act: An introduction to the comparative study of friendship patterns. In E. Layton (Ed.), The compact: Selected dimensions of friendship. Toronto: University of Toronto Press, 1974, pp. 15-32.

Farrell, W. The liberated man: Freeing men and their relationships with women. New York: Random House, 1974.

Fasteau, M. The male machine. New York: Dell, 1975.

Goldberg, $\mathrm{H}$. The hazards of being male: Surviving the myth of masculine privilege. New York: New American Library, 1976.

Goode, W., Hopkins, E., \& McClure, H. Social systems and family structures. Indianapolis: Bobbs-Merrill, 1971.

Hartley, R. Sex-role pressures and the socialization of the male child. Psychological Reports, $1959,5,457-468$.

Helmreich, R., Spence, J., \& Holahan, C. Psychological androgyny and sex-role flexibility: A test of two hypotheses. Journal of Personality and Social Psychology, 1979, 37, 1631-1644.

House, J. Social structure and personality. In M. Rosenberg \& R. Turner (Eds.), Social psychology: Sociological perspectives. New York: Basic Books, 1981, pp. 525-561.

Jourard, S. The transparent self. New York: D. Van Nostrand, 1971.

Knupfer, G., Clark, W., \& Room, R. The mental health of the unmarried. American Joumal of Psychiatry, 1966, 122, 841-851.

Lewis, R. Emotional intimacy among men. Joumal of Social Issues, 1978, 34, 109-121.

Lewis,-Beck, M. Applied regression: An introduction. Beverly Hills, Calif.: Sage, 1980.

Lynn, D. Parental and sex role identification: A theoretical formulation. Berkeley, Calif: McCutchan, 1969.

Maccoby, E., \& Jacklin, C. The psychology of sex differences. Stanford, Calif.: University Press, 1974.

Nie, N., Hull, C., Jenkins, J., Steinbrenner, K., \& Bent, D. Statistical package for the social science, 2nd ed. New York: McGraw-Hill, 1976.

Nye, F. The role structure and analysis of the family. Beverly Hills, Calif.: Sage, 1976.

Olstad, K. Brave new men: A basis for discussion. In J. Petras (Ed.), Sex: male/gender: masculine. Port Washington, N.Y.: Alfred, 1975.

Parsons, T. Family structures and the socialization of the child. In T. Parsons \& R. Bales (Eds.), Family socialization, and interaction process. Glencoe, Ill.: Free Press, 1955.

Pearce, W., Wright, P., Sharp, S., \& Slama, K. Affection and reciprocity in self-disclosing cornmunication. Human Communication Research, 1974, 1, 5-14.

Pleck, J. Man to man: Is brotherhood possible? In N. Glazer-Malbin (Ed.), Old family/new family: Interpersonal relationship. New York: D. Van Nostrand, 1975, pp. 229-244.

Powers, E., \& Bultena, G. Sex differences in intimate friendship of old age. Journal of Marriage and the Family, 1976, 38, 739-747.

Sattel, J. The inexpressive male? Tragedy or sexual politics? Social Problems, 1976, 23, 469-477.

Seiden, A., \& Bart, P. Woman to woman: Is sisterhood powerful? In N. Galzer-Malbin (Ed.), Old family/new' family? Interpersonal relationships. New York: D. Van Nostrand, 1975, pp. $189-228$.

Shulman, N. Life-cycle variations in patterns of close relationships. Journal of Marriage and the Family, 1975, 37, 813-822.

Spence, J., \& Helmreich, R, Masculinity/femininity: Their dimensions, correlates, and antecedents. Austin: University of Texas Press, 1978.

Wheeler, L., \& Nezleck, J. Sex differences in social participation. Journal of Personality and Social Psychology, 1977, 35, 742-754. 